\title{
Biological Control of Aflatoxin in Maize Grain at Ambient Storage Conditions
}

\author{
Meena Shekhar ${ }^{1}$, Nirupma Singh ${ }^{2 *}$, Sunaina Bisht ${ }^{2}$, Vimla Singh ${ }^{1}$ and Arvind Kumar ${ }^{2}$ \\ ${ }^{1}$ Indian Institute of Maize Research, Pusa Campus, New Delhi-12, India \\ ${ }^{2}$ Indian Agricultural Research Institute, Pusa Campus, New Delhi-12, India \\ *Corresponding author
}

\section{A B S T R A C T}

\begin{tabular}{|l|}
\hline Ke y w o r d s \\
$\begin{array}{l}\text { Maize, Biocontrol, } \\
\text { Aspergillus flavus, } \\
\text { Trichoderma asperellum, } \\
\text { Aflatoxin }\end{array}$ \\
\hline Article Info \\
\hline $\begin{array}{l}\text { Accepted: } \\
23 \text { March } 2018 \\
\text { Available Online: } \\
\text { 10 April } 2018\end{array}$ \\
\hline
\end{tabular}

\section{Introduction}

Aflatoxin contamination of crop is a worldwide food safety concern. Aflatoxins are a group of approximately 20 related fungal metabolites with major ones as $B_{1}, B_{2}, G_{1}$, and $\mathrm{G}_{2}$. Aflatoxin $\mathrm{B}_{1}\left(\mathrm{AFB}_{1}\right)$ is the most potent naturally occurring chemical liver carcinogen (IARC, 1993).

Long term exposure from moderate to low concentration of aflatoxin causes chronic toxicity. It is one of the most important causes for stunting in children and immune system disorders (Turner et al., 2003). Hence, their quantity in food and feed is closely monitored and regulated in most of the countries
(Egmond Van, 1995). Almost $40 \%$ of crop products are lost yearly due to aflatoxin contamination in developing world (Miller, 1996). Fungal deterioration of stored seed and grain is a chronic problem in the Indian storage system because of tropical hot and humid climate. These conditions lead to colonization of harvested grains by various species of Aspergillus leading to deterioration in quality of food/feed due to aflatoxin production. Aspergillus is the main fungus responsible for aflatoxin contamination. Mycotoxins are well known for their health hazardous effect in human beings and animals (Probest et al., 2007; Reddy and Raghavender, 2007). Among all the aflatoxin, particularly $\mathrm{AFB}_{1}$ is the most hazardous, causing damage 
such as toxic hepatitis, hemorrhage, edema, immune suppression and hepatic carcinoma.

In India, human disease outbreaks attributable to consumption of aflatoxin-contaminated maize have been reported from district of Banswara in Rajasthan and Panchmahal in Gujarat (Krishnamachari et al., 1975). Also, the occurrence of aflatoxins and ochratoxin A has been reported in poultry feeds from India (Gong et al., 2003; Thirmula Devi et al., 2002).

There are strict regulations on chemical pesticide use and there is a political pressure to remove the most hazardous chemicals from market. Although restrictions are being imposed to protect food quality and the environment, chemicals are still our only recourse at present to prevent disease of food crops. Therefore, it is important to find a practical, cost effective and non-toxic method to prevent fungal contamination of stored maize. Use of biocontrol agents provides an opportunity to avoid various chemical preservatives and fungicides. Wide arrays of organisms have been tested for biological control of aflatoxin contamination including bacteria, yeasts, actinomycetes and algae (Mishra and Das 2003). Keeping this in a view, studies were undertaken to elucidate the potential of biological agents isolated from maize grains to minimise the buildup of aflatoxin due to contamination of Aspergillus flavus in post-harvest maize.

\section{Materials and Methods}

Grains from three genotypes viz., HQPM-1, HM-4 and Bio- 9681 were surface sterilized for 1 minute in $2.5 \% \mathrm{NaOCl}$, washed in three changes of sterile distilled water and plated 10 kernels on each culture plates containing Potato Dextrose Agar (PDA) medium aseptically. Three replicates from each sample plated and incubated at $28^{\circ} \mathrm{C} \pm 2^{\circ} \mathrm{C}$ for three days. Fungal colonies on maize kernels visualized in stereo-binocular microscope (Olympus BH 2) counted and identified up to genus level as Fusarium, Trichoderma (Nelson et al., 1983); Aspergillus, Penicillium, and other fungi (Pitt and Hocking, 1997). Further from each sample, only fungi $A$. flavus, was selected (Singh et al., 1991). To obtain pure culture sub culturing was done for further study. These pure A. flavus isolates were enumerated AF-1 to AF-50, which were characterized on the basis of their toxicity as highly toxic; moderately toxic and non-toxic, with the help of Ammonia vapour test. Petri dishes were placed upside down and a drop (2 $\mathrm{ml}$ ) of concentrated ammonia solution (SRL Extra pure AR Grade) was poured into the lid of each inverted culture plate and kept for 1015 minutes to release ammonia vapour (Kumar et. al 2006).

\section{Laboratory assessments of antagonistic effect of biocontrol agents with Dual culture technique}

To assess the antagonistic effect of biocontrol agents; Trichoderma asperellum, T. viride and A. niger isolated from maize grains were purified and maintained on culture plate. Dual culture of bioagents and test pathogens were established to test the antagonistic activity. The PDA was inoculated at $1 \mathrm{~cm}$ distance from the edge of the Petri dish with a $5 \mathrm{~mm}$ mycelial disc cut from the leading edge of an active 5days-old colony of A. flavus and these biocontrol agents seperately. The plates were incubated at $28 \pm{ }^{\circ} \mathrm{C}$ for 5-6 days and the diameter of the inhibition zones of A. flavus growth, due to antagonistic activity, was measured in centimetres. The growth inhibition percentage (GIP) was expressed in terms of inhibition percentage of radial growth of the phytopathogen, i.e. by comparing with control plates without the presence of $T$. asperellum disc (Fig. 1 and 2). 
Effect of seed treatment of biocontrol agents in minimizing the aflatoxin in postharvest maize

Mass multiplication of biocontrol agents were accomplished on sorghum grains, prior soaked and autoclaved in a flask and incubated at 28 $\pm^{\circ} \mathrm{C}$ for a week (Fig. 3). Talcum formulations of these biocontrol agents were prepared after shade drying and grinding of these impregnated grains in to powder form and CFU adjusted at $10^{9}$ by adding talcum powder. The formulation of these biocontrol agents were tested on fresh harvest maize samples of genotypes HQPM-1; HM-4; and Bio 9681 @ 4 and $8 \mathrm{~g} / \mathrm{kg}$ grains. The sample size of each genotype was $2 \frac{1}{2} \mathrm{~kg}$.

Initial estimation of concentration of aflatoxin $\mathrm{B}_{1}\left(\mathrm{AFB}_{1}\right)$ of these grain samples were also done prior to start the experiment. The total grain samples of these genotypes were artificially inoculated with toxic isolate of $A$. flavus, (Af no. 8), before 24 hours to start the experiment @10mg spore biomass of $A$. flavus $/ \mathrm{kg}$ grains. After 24 hours each inoculated grain sample $\left(2 \frac{1}{2} \mathrm{~kg}\right) \mathrm{kept}$ in a separate gunny bags and treated with above biocontrol agents separately and kept in ambient storage condition for 4 months duration. Stirring of grains was done once in a month to maintain the uniformity in the samples with individual glass rod. At the end a total of $100 \mathrm{~g}$ of grain sample was taken from each replication for estimation of aflatoxin. The experiment was started in the month of August and estimation of aflatoxin from these maize grain samples was done by using Enzyme-Linked Immunosorbant Assay (ELISA) method after four month's storage period. The direct competitive ELISA method was followed. (A Training Course ICRISAT 2005). The statistical analysis was done by using the OD values obtained for AFB1 standards, taking AFB1 concentrations on the $\mathrm{X}$-axis and OD values on the $\mathrm{Y}$-axis (Fig. 5)
AFB1 $(\mu \mathrm{g} / \mathrm{kg}):(\mathrm{A} \times \mathrm{D} \times \mathrm{E}) / \mathrm{G}$

$\mathrm{A}=\mathrm{AFB} 1$ concentration in sample extract (ng/ml)

$\mathrm{D}=$ Times dilution with buffer

$\mathrm{E}=$ Extraction solvent volume used (ml)

$\mathrm{G}=$ Sample weight $(\mathrm{g})$

\section{Results and Discussion}

All the bioagents were found effective in minimising the radial growth of A. flavus. Among all $T$. asperellum overgrew the test pathogen when grown together in a single plate and found more effective in suppressing the growth of test pathogen (Fig. 4). In this study the potential of these biocontrol agents i.e., T. asperellum, T. viride and A. niger were studied in reducing the synthesis of $\mathrm{AFB}_{1}$ in post-harvest maize for four months duration. They were evaluated in two doses 4 and 8 $\mathrm{g} / \mathrm{kg}$. Among them T. asperellum was found most effective in inhibition the synthesis of $\mathrm{AFB}_{1}$ by $100 \%$ in $c v$. HQPM $-1 ; 96.32 \%$ in $c v$. HM-4 and 93.04 in $c v$. Bio $9681 @ 8 \mathrm{~g} / \mathrm{kg}$ whereas $T$. viride could inhibit the synthesis of $\mathrm{AFB}_{1}$ in $c v$. HQPM-1 by $88.24 \%$; in $c v$. HM4, $91.83 \%$ and in $c v$. Bio 968193.79 (Table 1) as compared to check.

The initial level of $\mathrm{AFB}_{1}$ concentration of these maize genotypes were $0.016 \mathrm{ppb}$ in $c v$. HQPM; 0.012ppb in $c v$. HM-4; and 0.031ppb in $c v$. Bio 9681 (Table $1 \mathrm{~A}$ and $\mathrm{B}$ ). This indicated that grains were not free from aflatoxin contamination and already carrying very small amount of infection from field itself and these grains may spoil in storage due to poor storage condition and consequently the aflatoxin level may increase in due course. To avoid further spoilage of grains, application of these biocontrol agents in post-harvest storage were found very effective. 
Table.1 Evaluation of biocontrol agents (isolated from maize grains) for reducing aflatoxin synthesis in maize grains (inoculated with AF no. 8 strain) after four months stored period

A. Effect of Biocontrol agents @ 4 gm/kg seeds inoculated by A. flavus on production of AFB 1 after 4 months storage period

\begin{tabular}{|c|c|c|c|c|c|c|c|c|c|c|c|c|}
\hline \multirow{2}{*}{$\begin{array}{l}\text { Biocontrol agents } \\
\text { used @ } 4 \text { gm/kg } \\
\text { seeds }\end{array}$} & \multicolumn{3}{|c|}{ Grain Moisture \% } & \multicolumn{3}{|c|}{ Germination \% } & \multicolumn{3}{|c|}{ AFB1 (ppb) } & \multicolumn{3}{|c|}{$\%$ Reduction in AFB1 } \\
\hline & $\begin{array}{l}\text { HQPM- } \\
1\end{array}$ & $\begin{array}{l}\text { HM- } \\
4\end{array}$ & $\begin{array}{c}\text { Bio } \\
9681\end{array}$ & $\begin{array}{l}\text { HQP } \\
\text { M-1 }\end{array}$ & HM-4 & $\begin{array}{l}\text { Bio- } \\
9681\end{array}$ & $\begin{array}{l}\text { HQPM- } \\
1^{*}\end{array}$ & $\begin{array}{l}\text { HM- } \\
4^{*}\end{array}$ & $\begin{array}{l}\text { Bio- } \\
9681^{*}\end{array}$ & $\begin{array}{l}\text { HQPM- } \\
1\end{array}$ & HM-4 & $\begin{array}{c}\text { Bio } \\
9681\end{array}$ \\
\hline T. asperellum & 13.0 & 13.1 & 13.3 & 2.0 & 50 & 100 & 1.978 & 9.789 & 1.1949 & 96.86 & 85.91 & 87.79 \\
\hline T. virede & 12.5 & 12.8 & 13.3 & 10 & 50 & 90 & 21.985 & 9.789 & 1.598 & 65.105 & 85.91 & 83.67 \\
\hline A. niger & 12.6 & 13.5 & 13.2 & 20 & 20 & 80 & 41.370 & 22.967 & 9.789 & 34.35 & 66.95 & 0.0 \\
\hline A. flavus ${ }^{I}$ & 12.3 & 13.5 & 12.9 & 10 & 40 & 100 & 63.005 & 69.496 & 9.789 & - & - & - \\
\hline $\begin{array}{l}\text { Check (No } \\
\text { treatment) }\end{array}$ & 13.0 & 13.7 & 13.1 & 10 & 43 & 100 & 64.00 & 18.57 & 3.21 & - & - & - \\
\hline
\end{tabular}

B. Effect of Biocontrol agents @ $8 \mathrm{gm} / \mathrm{kg}$ seeds inoculated by A. flavus on production of AFB 1 after 4 months storage period

\begin{tabular}{|c|c|c|c|c|c|c|c|c|c|c|c|c|}
\hline \multirow{2}{*}{$\begin{array}{l}\text { Biocontrol agents } \\
\text { used @ } 8 \mathrm{gm} / \mathrm{kg} \\
\text { seeds }\end{array}$} & \multicolumn{3}{|c|}{ Moisture \% } & \multicolumn{3}{|c|}{ Germination \% } & \multicolumn{3}{|c|}{ AFB1 (pplo) } & \multicolumn{3}{|c|}{$\%$ Reduction in AFB1 } \\
\hline & $\begin{array}{l}\text { HQPM } \\
-1\end{array}$ & $\begin{array}{l}\text { HM- } \\
4\end{array}$ & $\begin{array}{l}\text { Bio } \\
9681\end{array}$ & $\begin{array}{l}\text { HQPM- } \\
1\end{array}$ & $\begin{array}{l}\text { HM- } \\
4\end{array}$ & $\begin{array}{l}\text { Bio- } \\
9681\end{array}$ & $\begin{array}{l}\text { HQPM } \\
-1^{*}\end{array}$ & HM-4* & $\begin{array}{l}\text { Bio- } \\
9681^{*}\end{array}$ & $\begin{array}{l}\text { HQP } \\
\text { M-1 }\end{array}$ & $\begin{array}{l}\text { HM- } \\
4\end{array}$ & $\begin{array}{c}\text { Bio } \\
9681\end{array}$ \\
\hline T. asperellum & 11.8 & 13.3 & 13.3 & 10 & 60 & 100 & 0.009 & 3.371 & 0.938 & 100.0 & 96.32 & 93.04 \\
\hline T. viride & 12.5 & 13.3 & 13.2 & 20 & 20 & 95 & 12.554 & 7.499 & 0.836 & 88.24 & 91.83 & 93.79 \\
\hline A. niger & 12.9 & 13.3 & 12.8 & 30 & 10 & 85 & 45.422 & 28.425 & 11.231 & 57.46 & 69.04 & 16.67 \\
\hline A. flavus ${ }^{I}$ & 13.1 & 13.3 & 13.1 & 10 & 30 & 100 & $\begin{array}{l}106.78 \\
5\end{array}$ & 91.825 & 13.478 & - & - & - \\
\hline $\begin{array}{l}\text { Check (No } \\
\text { treatment) }\end{array}$ & 13.0 & 13.7 & 13.1 & 10 & 43 & 100 & 64.00 & 18.57 & 3.21 & - & - & - \\
\hline
\end{tabular}


Fig.1 A. Healthy maize grains B. Aspergillus contaminated grains
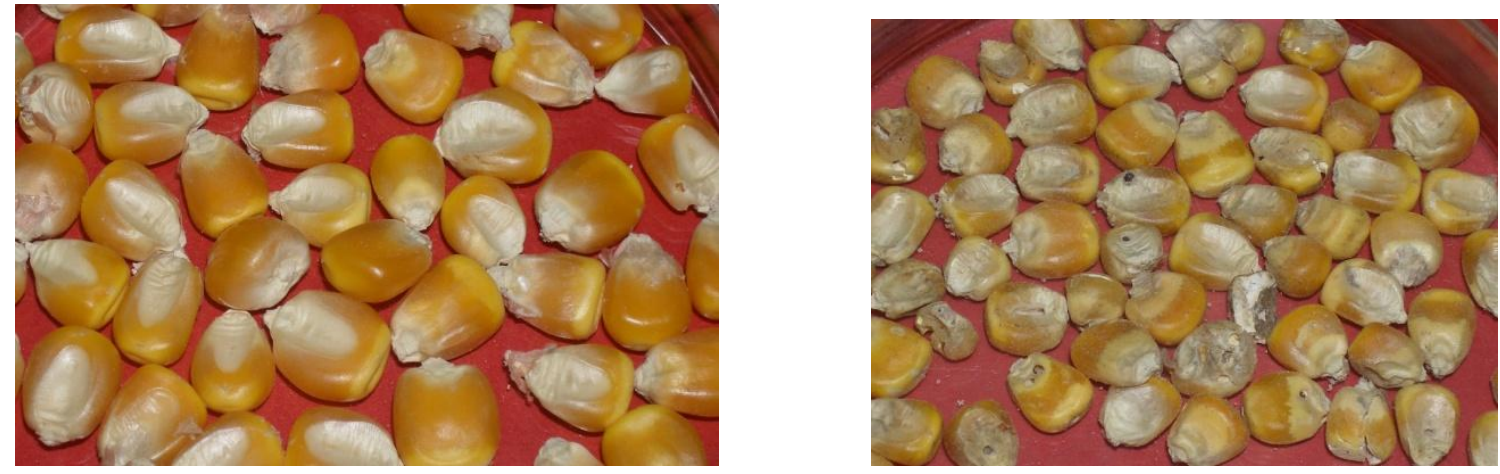

Fig.2 Aflatoxin molecule

Fig.3 Mass multiplication of biocontrol agents
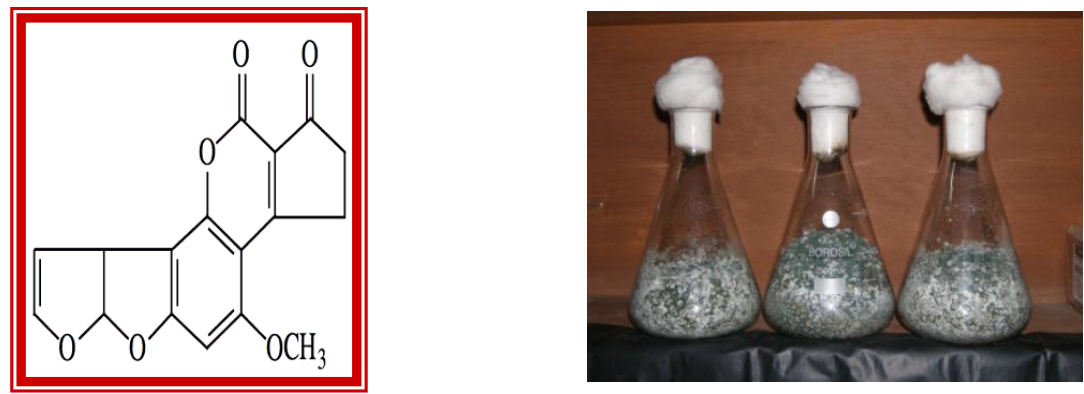

AFB1

Fig.4 Trichoderma asperellum and Aspergillus niger inhibiting the growth of A. flavus
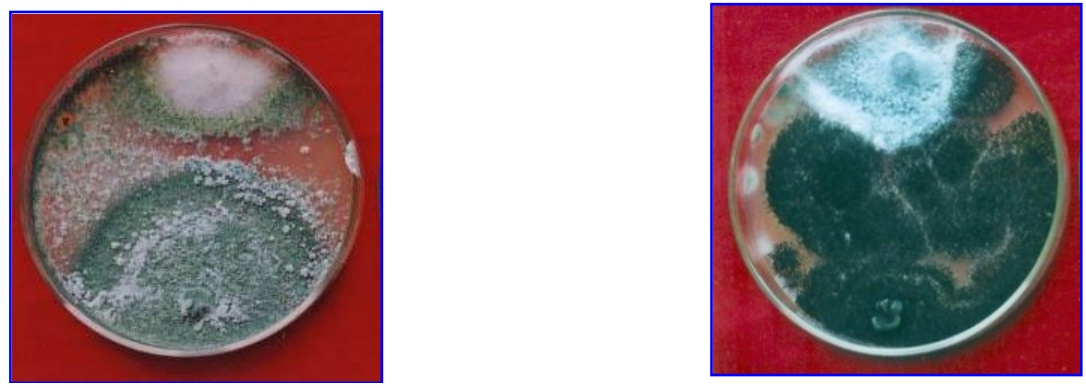

Fig.5 Graph based on the different concentration of standard

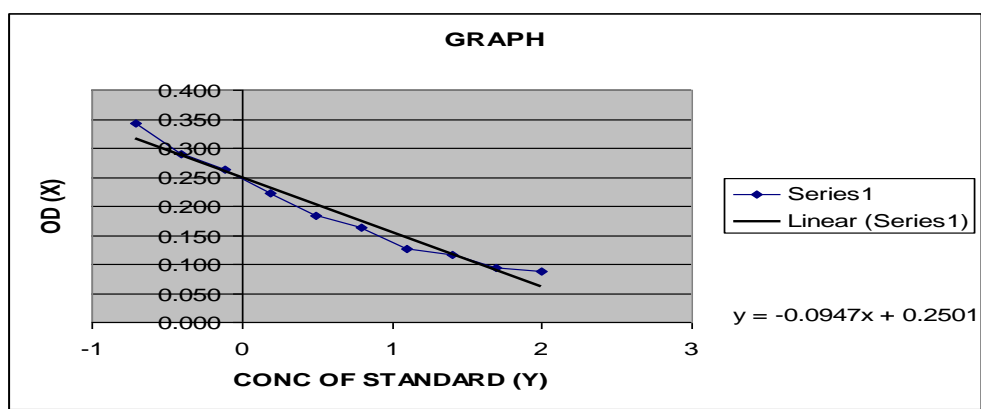


T. asperellum inhibited the synthesis of $\mathrm{AFB}_{1}$ up to $100 \%$ in $c v$. HQPM-1 @ $8 \mathrm{gm} / \mathrm{kg}$ grain as compared to check. The initial concentration of $\mathrm{AFB}_{1}$ in $c v$. HQPM-1 was $0.016 \mathrm{ppb}$ which goes up to $106.78 \mathrm{ppb}$ when artificially inoculated with toxic strain of $A$. flavus in four months duration which is above the permissible limits (20ppb) whereas the grain treated with $T$. asperellum exhibited concentration of $\mathrm{AFB}_{1} \quad 0.009 \mathrm{ppb}$ and $0.938 \mathrm{ppb}$ in Bio 9681. 100\% reduction in aflatoxin build-up was observed when treated with T. asperellum and E.L. Katatny et al., (2001) was also observed that the inhibition activity of $T$. asperellum was likely due to antimicrobial effects when co-cultured with other organism. It is therefore hypothesized that the $T$. asperellum and $T$. viride considered in this study probably produced an array of enzymes with antimicrobial effect against the A. flavus. Gachoma and Kotchoni (2008) suggested that the Trichoderma sp. can effectively control aflatoxin contamination of aflatoxin in peanut kernels. The production of volatile and extracellular enzymes by $T$. asperellum isolates may have been sufficient to suppress the growth of maize molds, responsible for AFB1 production and consequently a lower production of aflatoxin synthesis.

The study showed that the aflatoxin concentration is minimized, which may be an indirect effect of the suppressed growth of aflatoxigenic fungi A. flavus by $T$. asperellum leading to assumption that fewer colonies produced less aflatoxin. The antimicrobial effect of $T$. asperellum might be a potential source of anti-pathogenic activity that can be used to control aflatoxin build up in postharvest maize. This may be linked to the chitinase activity displayed by $T$. harzianum. Chitinase is believed to be a key enzyme in mycoparasitism hypothesis presented by Howell (2003). The bio control agent, Trichoderma species have been successfully used in minimising aflatoxin build-up due to their high reproductive capacity, efficient utilization of nutrients, strong aggressiveness against other phytopathogens, efficiency in promoting plant growth and defence mechanism and ability to modify the rhizosphere (Kleifeld and Chet, 1992; ElKatatny et al., 2001; Benítez et al., 2004). Based on our findings we concluded that the likely mechanisms by which Trichoderma species suppressed A. flavus in maize might involve production of volatiles and/or production of extracellular enzymes. This is an important finding because it opens the opportunities for further study the underlying antagonistic mechanisms of the genus Trichoderma to efficiently minimise aflatoxin contamination of crop products.

\section{References}

A training course manual on "Aspergillus flavus seed infection and aflatoxin estimation by ELISA" and Aflatoxin management option in groundnut 13-17 June 2005, ICRISAT, Patancheru, India Benítez T, Rincón AM, Limón MC, Codón AC. Biocontrol mechanisms of Trichoderma strains. (2004) Int Microbiol; 7: 249-260.

Egmond, V., H.P., Dekker, W.H., 1995. Worldwide Regulations for mycotoxins in 1994. Natural toxins 3:332-6.

El-Katatny MH, Somitsch W, Robra KH, ElKatatny MS, Gübitz GM. Production of Chitinase and $\beta-1,3$ glucanase by Trichoderma harzianum for Control of the Phytopathogenic Fungus Sclerotium rolfsii. (2000) Food Technol Biotechnol.; 38: 173-180.

Gong, Y.Y., Egal, S., Hounsa, A., Turner, P.C., Hall, A.J., Cardwell, K.F., Wild, P.C. 2003. Determinants of aflatoxin exposure in young children from Benin and Togo, West Africa: the critical role 
of weaning. International Journal of Epidemiology 32: 556-562.

Howell CR. Mechanisms employed by Trichoderma species in the biological control of plant diseases, the history and evolution of current concepts.(2003) Plant Dis.;87:4-10. doi: 10.1094/ PDIS.2003.87.1.4

IARC-International Agency for Research on Cancer 1993. Some naturally occurring substances: Food items and Constituents, Heterocyclic Aromatic Amines and Mycotoxins. IARC Monographs on the Evaluation of Carcinogenic Risks to Humans, 56: Geneva: 489-521

Krishnamachari, K.A.V.R., Bhatt, R.V., Nagarajan, V., Tilak, T.B.G., 1975. Hepatitis due to Aflatoxicosis-an outbreak in Western India. Lancet: 1061-1062.

Kumar, S., Shekhar, M., Kumari, A., Khan, A.A., Archana, 2009. Manual for estimation of aflatoxin from maize grains by ELISA and HPLC. DMR Technical Bulletin No. 2009/1(pp22).

Miller, J.D., 1996. Mycotoxins. Proceedings of the Workshop on Mycotoxins in
Food in Africa, November 6-10, 1996, International Institute of Tropical Agriculture, Benin, pp: 18-22.

Mishra, H.N. and Das, C., 2003. A review on biological control and metabolism of aflatoxin. Critical Reviews in food Science 43: 245-264.

Probst C, Njapau H. Cotty PJ (2007). Outbreak of an Acute aflatoxicosis in Kenya in 2004: Identification of the causal agent. Appl. Env. Microbiol., 73: 2762-2764.

Reddy BN, Raghavender CR. Outbreaks of aflatoxicoses in India. Afr J Food Agric Nutr Dev. 2007; 7: 5

Thirmula, D.K., Mayo, M.A., Reddy, G., Reddy, D.V.R., 2002. Occurrence of aflatoxins and ochratoxin A in Indian poultry feeds. Journal of Food Protection 65: 1338-1340.

Turner, P.C., Moore, S.E., Hall, A.J., Prentice, A.M., Wild, C.P., 2003. Modification of immune function through exposure to dietary aflatoxin in Gambian children. Environmental Health. Perspectives 111: 217-220.

\section{How to cite this article:}

Meena Shekhar, Nirupma Singh, Sunaina Bisht, Vimla Singh and Arvind Kumar. 2018. Biological Control of Aflatoxin in Maize Grain at Ambient Storage Conditions. Int.J.Curr.Microbiol.App.Sci. 7(04): 3031-3037. doi: https://doi.org/10.20546/ijcmas.2018.704.343 